\title{
ARTÍCULO RESEÑA
}

\author{
¿LA JUSTICIA DE DIOS?: \\ GUERRAS SANTAS Y \\ MÁRTIRES, HOY Y SIEMPRE
}

\author{
ADRIÁN MUÑOZ \\ El Colegio de México
}

ANTONIO RuBial, La justicia de Dios: la violencia física y simbólica de los santos en la historia del cristianismo, México-Madrid, Ediciones de Educación y Cultura-Trama Editorial, 2011, 272 pp.

Good is Heaven. Evil is Hell

WILLIAM BLAKE

En enero de 2002, George W. Bush ofreció su discurso del Estado de la Unión. Allí, el entonces presidente habló de un "Eje del Mal" (axis of evil) que incluía a Irán, Iraq y Corea del Norte, acusados de sostener políticas que fomentaban el terrorismo. ${ }^{1}$ El término, como es de esperar, levantó mucha polémica y discusiones intelectuales, pero lo que me interesa destacar es el término mismo, más que sus accesorios. Al usar la palabra "Mal", Bush estaba de manera voluntaria o involuntaria evocando un discurso religioso. No es lo mismo hablar de "criminales" que de "malignos". Los miembros de dicho Eje, pues, son encarnaciones políticas y belicosas de fuerzas maléficas, casi satánicas. Las implicaciones son en realidad obvias: hacerles frente implica librar una lucha en nombre del Bien, con mayúscula. La luz contra la oscuridad. Y ello, casi de manera natural,

${ }^{1}$ George W. Bush, “Text of President Bush's 2002 State of the Union Address”, The Washington Post, 29 de enero de 2002. 
deriva en una suerte de invocación a una guerra santa, a una nueva cruzada.

En el discurso de Bush encontramos una violenta retórica inspirada por una violencia religiosa milenaria, el tema principal que Antonio Rubial desarrolla en su libro La justicia de Dios, un volumen que posee el inestimable mérito de la ansiada combinación académica de erudición, elocuencia y fluidez. Lo que me interesa no es tanto intentar un resumen de las ideas y la organización del libro, como ponderar sobre algunos de los puntos cruciales que la obra suscita; sobre todo hay que pensar de qué manera un libro como éste se relaciona con el mundo que nos ha tocado vivir. Las temáticas del libro de Rubial, de hecho, poseen una relevancia importante en el contexto actual de la política en Medio Oriente, aunque no trate directamente de ello. En la actualidad, pensar en el mundo islámico resulta indisoluble de un imaginario violento que implica, directa o indirectamente, a un Occidente que se presume cristiano en términos mayoritarios. A un libro se le hace justicia cuando se construye un diálogo con él, cuando dejamos que nos apremie a reflexionar sobre sus temas y premisas.

La aparición de este volumen debe celebrarse con toda justicia: si por un lado se trata de un trabajo bien documentado, por el otro ofrece una lectura amena y fluida. De ningún modo se convierte en un mero recuento de nombres, fechas y lugares, sino que La justicia de Dios constituye una muy disfrutable historiografía de los ejes clave que han tejido la trama de la violencia en la cristiandad. Básicamente, consta de tres capítulos dedicados a los ejes principales: 1) "La guerra sagrada", 2) "La justicia implacable", y 3) "El cuerpo victimado"; los temas desarrollados van desde la concepción de Dios como el "Señor de los Ejércitos” y las Cruzadas, hasta prejuicios antisemitas y la poderosa imagen del mártir y la flagelación corporal. Desde luego, cada uno de estos ejes podría dar pie a libros exclusivamente dedicados a ellos, pero lo que Rubial hace de manera perspicaz es leer dichos ejes articuladamente y advertir cómo se concatenan e implican unos a otros.

A primera vista parecería que invocar el discurso de Bush no tiene mucho que ver con este libro, el cual se aboca más a cuestiones antiguas y medievales, pero dicho equívoco deriva 
de la incapacidad de advertir las continuidades históricas y simbólicas de mundos y tipologías culturales. Las consideraciones aquí vertidas surgen de apuntes hechos a partir de mi primera lectura del libro, recién apareció; poco a poco fui reformulándolos al pensar en la situación contemporánea de los mundos religiosos en guerra, sobre todo en Medio Oriente, y porque los temas de La justicia de Dios están vinculados con ideas acerca del "terrorismo".

Rubial comienza el libro de la siguiente manera:

A partir de que la violencia sigue llenando nuestros espacios cotidianos, la actitud hacia ella ha cambiado sustancialmente a partir de la modernidad. En la cultura occidental anterior al siglo xIX, ésta se consideraba como algo natural. De hecho, la humanidad durante milenios percibió el cosmos como un espacio de lucha entre principios opuestos, como la única condición de posibilidad para la existencia del universo (p. 11).

El autor parece ceñirse a una noción según la cual el periodo antiguo (en oposición a la modernidad) constituía un mundo "encantado" que operaba en función de instrumentos y factores sagrados. La oposición invocada revela la eterna lucha entre el bien y el mal, una pugna que, por "sagrada", pareciera no estar presente en la modernidad. Dudo que sea así. La creciente secularización no sólo de Occidente sino del mundo contemporáneo difícilmente ha erradicado la sensación subyacente de una batalla entre fuerzas benignas y malignas. Las maneras como se defiende o infama a los participantes en diferentes conflictos bélicos aún poseen dicho cariz; lo ejemplifica el discurso de Bush (en el contexto político) y se traduce en los modos en que los católicos (en un contexto cultural) se refieren a varios grupos protestantes.

No cabe duda de que el poder religioso y el poder político han operado conjuntamente en la historia del cristianismo; de hecho, en muchos sentidos, ello ha proporcionado la base sobre la cual se han construido iglesias, reinados y arduos debates. El poder y la autoridad real han estado amparados por la autorización y el poder religiosos. En el mundo cristiano, la sacralización del poder cristalizó de manera importante en la iconografía bizantina desde el siglo $\mathrm{v}$, donde destacan, por ejemplo, representaciones de emperadores con halos o de Jus- 
tiniano realizando ofrendas en la iglesia de Rávena. Pero aún más significativo fue la "moda", en el siglo vI, de representar a Cristo en atavíos de emperador guerrero (p. 29). Si bien la prédica evangélica expresaba un discurso pacífico y, al menos en teoría, amoroso, esta imagen de Cristo revierte dicha postura; de hecho, está más cerca del Yahvé como Señor de los Ejércitos y será crucial para la concepción simbólica de las Cruzadas. En los siguientes siglos (VI-VII) se hizo uso también de las figuras de los reyes santos, David y Salomón, como ejemplos de los protectores paradigmáticos de la Iglesia (p. 31).

Dios -o la motivación religiosa- es una pieza crucial en nuestros lenguajes morales y políticos. Como el autor de La justicia de Dios discute, por ejemplo, los procesos de canonización de santos y reyes en la Europa cristiana implican una economía eficiente de la violencia, una economía que ha administrado la intimidación y el sufrimiento corporales y simbólicos de formas varias, y que también ha mutado los escenarios para su aplicación (capítulo III). Más allá de nuestras creencias personales, todo parece indicar que la gran mayoría de las personas creemos en dos tipos de acciones que emanan, respectivamente, de las ideas del bien y el mal (con o sin un aparato metafísico por detrás). Y el mal, en tanto se le concibe como una afrenta hacia el bien, merece castigarse violentamente. Aunque simplista, ésta es la premisa básica que ha servido de pretexto a infinidad de campañas bélicas a lo largo de la historia, incluidas las Cruzadas y la llamada guerra contra el terrorismo.

El sostenido discurso que se apoyaba en la simbólica oposición de la luz divina a las tinieblas satánicas ha fundamentado una larga lista de conflictos y justificado cualquier cantidad de empresas bélicas. Aquí lo más importante es notar que no se trataba (ni en la Cruzadas ni en otros casos) de situaciones pasajeras, sino a todas luces longevas; se veían como parte de una interminable guerra contra el mal. Como escribe Rubial:

Una teología que consideraba la historia humana como una guerra permanente entre la ciudad de los hijos de Dios, el pueblo elegido de la nueva Jerusalén, y la de los seguidores de Satanás, no podía más que promover la esperanza de que estos últimos serían vencidos con violencia al final de los tiempos y castigados eternamente con sufrimientos indescriptibles (p. 12). 
¿Pero acaso tal panorama caducó en algún momento? Tal parece que la obstinación con que unos y otros se apegan a su programa simbólico-bélico posee tanta vigencia ahora como en el pasado. Alejandro Nadal, en una columna publicada en $\mathrm{La}$ Jornada, escribe acerca del conflicto entre Palestina e Israel: "la desmesura de los ataques de Israel hacen pensar en otro tipo de designios y de empresa. En realidad el objetivo militar es anular la esperanza y enfatizar el mensaje de que el pueblo palestino no tiene alternativa, carece de salida y debe abandonar cualquier expectativa sobre el surgimiento de un Estado autónomo". ${ }^{2}$ Estas palabras son inquietantemente similares a las de Rubial. Si bien Rubial habla de una teología cristiana empecinada en aniquilar a pueblos infieles, los "designios" a los que se refiere Nadal operan en el mismo tenor. Y lo mismo es aplicable en esa óptica a los guerrilleros de Hamas y otros grupos extremistas armados.

En todos estos casos, la configuración del otro es alevosa y despiadada; no hay cabida a la simpatía. Como sucedió con teólogos y predicadores desde al menos el siglo XII, los voceros de todos esos grupos son "grandes difusores del nuevo Demonio" (p. 160). Por supuesto, tal visión recurrió a las poderosas imágenes del averno y los castigos infernales que la literatura cristiana había desarrollado durante siglos. Los creyentes estaban plenamente convencidos de que el mal y sus emisarios eran reales y de que actuaban constantemente en nuestra tierra; por ello, era ineludible declarar una guerra santa al maligno, en cualquiera de sus manifestaciones:

A pesar de estar confinado en su reino infernal, Satán ejercía un insólito poder en la Tierra gracias al apoyo de ministros y seguidores que vivían no sólo fuera de la cristiandad, como los musulmanes, sino dentro de ella (judíos, homosexuales, ermitaños, rebeldes, herejes y brujas). El triunfo del bien sobre el mal dependería por tanto de la persecución efectiva contra esos enemigos (p. 151).

Al menos en parte, la construcción de infiernos tanto en la literatura canónica como extracanónica estuvo ligada a la creación de un sitio intermedio entre el cielo y el infierno; a

${ }^{2}$ Alejandro Nadal, “Gaza: los designios de Israel”, La Jornada, 6 de agosto de 2014. 
saber, el purgatorio, del cual no se habla explícitamente en las Escrituras. En realidad, este nuevo espacio temporal no apareció sino hasta el siglo XIII (p. 164) y si bien tenía la finalidad de combatir la culpa y el pecado, también participaba de un escenario cruento e ígneo.

La obra de Rubial ayuda a inspeccionar la historia del terrorismo moral o psicológico que la Iglesia romana ha manejado en distintos periodos; así también, en cierto sentido, nos puede servir para entender las políticas de la violencia discursiva en la actualidad. Como apunta el autor, en el Catecismo romano del siglo XVI se explicaba que los castigos de los pecadores podían ser de dos tipos: la "pena de daño" (es decir, la ausencia de Dios) y la "pena de sentido" (o sea, la laceración a manos de demonios en el fuego eterno). El texto referido, además, estipulaba que esto era dogma y que resultaba útil "para aterrar a los malos" (p. 162). La noción de los infiernos, con sus espeluznantes imágenes, ha sido siempre un importante factor para procurar la conversión y apuntalar la devoción cristiana. Los católicos, además, añadieron a la topografía teológica un tercer plano, intermedio entre el cielo y el infierno, el purgatorio. La existencia de un purgatorio aseguraba la eventual entrada al cielo a todos los pecadores, previo arrepentimiento, que muchas veces podía obtenerse mediante indulgencias y otros favores económicos. En el mismo tenor, cabe reparar en otro plano no explicado en el canon bíblico, pero que también se convirtió en un símbolo de tremenda fuerza ideológica y doctrinal (y hasta literaria): el limbo. Si los transgresores podían arrepentirse y pagar su estancia postrera en los cielos, los inocentes - sobre todo niños- que no habían tenido siquiera la oportunidad de conocer la fe verdadera irían al limbo, donde penarían indeterminadamente.

Lo más interesante no es sólo la importancia doctrinal que todos estos parajes simbólicos tuvieron durante la Edad Media, sancionados o ignorados por la Biblia. Llama la atención que siempre hubo diferentes percepciones en torno de los planos celestiales e infernales. Si estas discrepancias se suscitaban con un reino más o menos aceptado por toda la cristiandad, mucha más divergencia habría entonces con el purgatorio y el limbo. Recordemos que hace apenas unos pocos años se dio un inten- 
so debate en torno del limbo. Las noticias hablaban de la abolición del limbo, juna barbaridad! Si bien se trata de un artículo de fe, fundamental para la sensibilidad católica durante al menos ocho siglos, la verdad es que el limbo nunca fue realmente un dogma sancionado de manera formal por la teología eclesiástica.

Pero si raya en lo absurdo la idea de abolir, de pronto, la existencia de un plano tan influyente como éste, ni qué decir de posteriores consideraciones acerca del infierno. La discusión sobre el limbo estuvo encabezada por el entonces cardenal Joseph Ratzinger, después nombrado como el papa Benedicto VI. En 1999, el papa Juan Pablo II había atenuado la metafísica realidad del purgatorio y el infierno, al afirmar que se trataba de estados de purificación y de ausencia de Dios. ${ }^{3}$ En 2007, además de la "cancelación" del limbo, Benedicto XVI dogmatizó: el infierno sí existía y era eterno. ${ }^{4} \mathrm{~A}$ inicios de 2011, sin embargo, pareció revirar: ni el purgatorio ni el infierno eran lugares físicos, sino estados mentales o del espíritu, ${ }^{5} \mathrm{y}$ aún en 2014 el tema sigue vigente. En medio de la incertidumbre y desinformación mediática se ha atribuido al papa Francisco la siguiente opinión: "Al igual que la fábula de Adán y Eva, vemos el infierno como un recurso literario". ${ }^{6}$

Resulta imposible no sentirse incómodamente burlón o atónitamente incrédulo. Los grandes reinos o planos que rigieron la fe de millones de personas durante la historia del catolicismo - ahora resulta- pueden cambiar de domicilio o, simplemente, dejar de existir. ¿Irá también el cielo a mudarse; reconocerá el Vaticano que el cielo es también un estado mental, para ser consecuentes con el resto de la polémica? ¿Es el cielo también una metáfora de la recompensa psicológica a las "buenas acciones"? Y si toda esta topografía religiosa se tornara en un conjunto de símbolos psicológicos, ¿qué papel jugaría entonces el mártir? Sus fundamentos estarían tan trastocados, que correría el ries-

${ }^{3}$ Cf. Juan Pablo II, "El infierno como rechazo definitivo de Dios", Aciprensa, 21 de julio de 1999, y Aciprensa, "El purgatorio: purificación necesaria para el encuentro con Dios", s.f.

${ }^{4}$ La Jornada, "Decide el Vaticano abolir el limbo", 21 de abril de 2007. de 2011

5Juan G. Bedoya, "El Papa se enreda con el purgatorio", El País, 13 de enero

${ }^{6}$ Radiopanamericana.com, "Papa Francisco: el infierno no existe y Adán y Eva son una fábula", 16 de abril de 2014. 
go de desaparecer también. Pero el martirio ha sido una pieza central en la construcción de la cristiandad, y concretamente de la Iglesia católica.

El martirio podía usarse como apología del ataque contra los gobernantes tiranos o de la conversión de los rebeldes en mártires, advierte Rubial. Nótese aquí la analogía parcial con la figura del mártir musulmán, o shahid. Si bien la naturaleza del camino al istishbad, o martirio, se ha convertido en objetivo principal de la censura occidental, sus orígenes tienen - al igual que el de los mártires cristianos- un sustrato religioso volcado hacia lo político, que implicaba tanto dar testimonio de una fe como padecer tortura a causa de dicha fe. Los mártires islámicos son ahora famosos sobre todo por sus empresas terroristas y sus suicidas bombarderos; con ese acto, el sujeto musulmán se convierte en shabid y obtiene un lugar en el paraíso. Sin embargo, una de las manifestaciones políticas más relevantes de la istishhad en la historia moderna se dio significativamente entre musulmanes, no con fuerzas islámicas en contra de poderes occidentales. El escenario fue una guerra entre facciones islámicas en el golfo Pérsico. Un joven de trece años se convirtió en un paradigmático shabid al hacerse detonar bajo un tanque durante la guerra entre Irán e Iraq en la década de 1980. El ayatola Khomeini elogió el acto y, de manera tácita, abrió las puertas a una larga carrera militar que empezó a hacer uso de esta técnica cada vez con mayor fervor. Los actos "martíricos" en Jerusalén siguen esta tónica.

Ahora bien: esta faceta islamista del shabid en realidad no se asemeja tanto al mártys cristiano, como sí a un integrante de la militia dei, o soldado de Dios, aspecto de la violencia cristiana que aborda Rubial. La figura del shabid, desde luego, debe leerse a la luz de la jihad -en su interpretación como guerra santa-, pero no es privativa del islam; ya san Agustín, en una apología de la defensa armada de la Iglesia, expresaba que "no obran injustamente quienes hacen una guerra justa" (p. 48; mi énfasis). En el siglo XI, el monje francés Bernardo de Claraval afirmaba: "El caballero de Cristo no tiene por qué temer matar al enemigo; es el ministro de Dios para el castigo de los malvados. En la muerte de un pagano se glorifica al cristiano porque se glorifica a Cristo” (p. 63). Un soldado de 
Dios combate en particular contra un no creyente, y en la Edad Media ese otro - desde la óptica cristiana- por lo general fue el musulmán; las Cruzadas fueron la forma más drástica que esta enemistad adoptó. Si lo pensamos bien, el discurso de Bush evoca ese mismo antagonismo. El tío Sam es el soldado predilecto de Dios y la familia Bush ha sido su más fiel general. Al mismo tiempo, en la cita anterior podemos intercambiar "cristiano" por "judío" o "musulmán" y seguiría valiendo con la misma fuerza.

La figura del shabid ha estado presente en los conflictos bélicos entre los musulmanes (tanto shiitas como sunitas); un enfrentamiento que repite las hostilidades entre católicos y protestantes, igualmente dramáticas tanto en Irlanda como en algunas zonas rurales de México, por mencionar sólo dos instancias. No obstante, la literatura hagiográfica utilizada por Rubial revela otro antagonismo, en particular porque la reyerta católico-protestante no tuvo lugar sino hasta el siglo XvI. Además de la satanización de musulmanes, la martirología cristiana suele también estigmatizar a los judíos. Aquí resultan ilustrativas sobre todo las narraciones de los santos inocentes.

Los primeros "santos inocentes" se refieren a los primogénitos judíos mandados asesinar por el rey Herodes según el Evangelio de Mateo (pp. 176-177). Siglos más tarde, la hagiografía se encargó de agregar el martirio de pequeños infantes a manos de judíos despiadados, sobre todo en España (p. 184). Como la mayoría de los episodios hagiográficos, es muy dudoso que esto haya sucedido de verdad, mas lo que sin duda refleja es un creciente sentimiento antisemita; de hecho, puesto que los árabes también son pueblos semitas (es decir, que hablan una lengua semítica y que tradicionalmente descienden de Sem, el hijo mayor de Noé, y de Ismael), el corpus cristiano que Rubial consulta es absolutamente antisemita. Por ejemplo: Rubial repara por un momento en las diversas representaciones de los martirios en el arte pictórico: los victimarios comúnmente aparecen ataviados con vestimentas musulmanas, quienes son referidos en la literatura como los "demoníacos ministros de Satán" (pp. 186, 190).

Una vez más regresamos al discurso de Bush y la mención del Eje del Mal, cuyos representantes más notorios eran Irán e 
Iraq. A propósito de los sucesos del 11 de septiembre de 2001, George Bush condenó severamente los ataques, al tiempo que elogiaba los valores enarbolados por Estados Unidos (la libertad, las oportunidades), los cuales ponían a esta nación por encima de todas las demás; además, aseguró: "nadie evitará que esta luz siga brillando. El día de hoy, nuestra nación ha conocido la maldad [evil] - lo peor que hay en la naturaleza humana- y nosotros hemos respondido con lo mejor que tiene Norteamérica”. El entonces presidente encomiaba a su pueblo a confiar en la providencial participación de un "Poder más grande que nosotros" y a soportar la afrenta con dignidad y templanza, para lo cual citó el Salmo 23. Como es de esperar, un discurso así no podría sino culminar con un proverbial " $G o d$ Bless America". ${ }^{7}$ Bush invocaba de manera consciente el eterno conflicto entre la luz y la oscuridad. Desde luego, no resultará sorpresivo que el ayatola Khomeini, a su vez, se haya referido con frecuencia a Estados Unidos como "Iblis", el diablo, y que a menudo el discurso político iraní, y después de otras naciones y agrupaciones islámicas también, hablaran del Gran Satán, categoría que comprendía, sobre todo, a Estados Unidos y Gran Bretaña (asimismo, a la Unión Soviética se le llamaba el Pequeño Satán). La política tiene con mucha frecuencia una motivación religiosa, aunque sea simbólicamente.

Desde luego, en épocas más modernas el infierno ha perdido su poder disuasivo, a la par que han aumentado los alcances de las actividades violentas, que muchas veces parecen salidas del mismísimo infierno. Dejando de lado la violencia vinculada con la delincuencia (descarnada, desmedida y brutal), la otra violencia, la política, aún conserva su cariz religioso, al menos si la relación entre las facciones en pugna involucra pueblos, naciones o comunidades cuya identidad está construida sobre un “ADN" religioso: hindúes vs. musulmanes vs. sikhs en el sur de Asia, católicos vs. protestantes en Irlanda, judíos vs. musulmanes en Oriente Medio... En cierto sentido, se trata de una fobia ancestral al otro; por ancestral, quizá más difícil de extirpar. Ha estado presente en el discurso de Bush o de Khomei- 
ni; también en el de grupos armados, políticos y líderes más recientes, como Osama Bin Laden o el Estado Islámico.

Ayelet Shaked, abogada y congresista israelí, ventiló en una red social, apenas en julio de 2014, su actitud hacia a los palestinos: los habitantes de Palestina son, para ella, todos terroristas y aun peor: serpientes que deben ser aniquiladas. ${ }^{8}$ La respuesta que el Estado de Israel debería tener con Palestina es descomunal: eliminar a todos los palestinos, en especial a las madres palestinas para evitar que sigan pariendo “serpientes". Una vez más, el término "serpiente", en un contexto como éste, difícilmente puede desligarse de un significado simbólico. Se trata de un animal impuro en la ley mosaica y, desde luego, posee un eco bíblico, demasiado bíblico. La primera criatura antagónica de Dios en la Biblia es la serpiente, que en Génesis incita a Eva a probar del fruto prohibido. (La cristiandad — siglos más tarde- se encargará de identificar a esta serpiente con Luzbel y el diablo). Sin duda hubo reacciones al pronunciamiento de Shaked. Recep Tayyip Erdogan, primer ministro de Turquía, ha condenado las palabras de la militante israelí. ¿Y en qué términos? Significativamente, decidió censurar la postura de Shaked al invocar al otro por excelencia de la identidad judía moderna: Hitler. Erdogan expresó que las intenciones de exterminio articuladas por Shaked eran análogas a las del régimen nazi. ${ }^{9}$ Cierto: en estricto sentido el nazismo no es un movimiento o tradición religiosa, pero simbólicamente opera como una manifestación del mal que aqueja al pueblo de Israel. Fue la versión moderna del mal, en el siglo xx, de la antigua Nínive o de Asiria. (Significativamente, también Fidel Castro ha compartido el tono condenatorio, al referirse a un "Holocausto palestino en Gaza”). ${ }^{10}$

También a finales de julio de 2014, Ron Dermer, embajador de Israel en Estados Unidos, dio una conferencia en el marco de la Cumbre de Cristianos Unidos por Israel. Además

${ }^{8}$ Cf. Jonathan Turley, “They Have To Die': Israeli Politician's Comments Calling For Killing of Mothers of Palestinians Trigger International Backlash”, Jonathanturley.org, 1 de julio de 2014.

${ }^{9}$ Cf. Rivka Salomon, "Erdogan to MK Ayelet Shaked: You Have Hitler's Mentality", Jerusalemonline.com, 13 de octubre de 2014.

${ }^{10}$ Cf. Aristegui Noticias, "'Holocausto palestino en Gaza', artículo de Fidel Castro", 5 de agosto de 2014. 
de la polémica declaración de que el ejército israelí debía ser condecorado con el Premio Nobel de la Paz, recurrió a los mismos tropos frecuentemente utilizados. Llamó a Irán el "Gran Mal" (Great Evil) y a Hamas el "pequeño mal” (little evil). En tono sardónico, incluso se refirió a Hezbollah como un "mal mediano" (medium-size evil). ${ }^{11}$ (Nótese la paráfrasis del Gran y el Pequeño Satán, antes referidos.) Desde luego, él también ha sido objeto de críticas tanto dentro como fuera de la comunidad judía alrededor del orbe. ${ }^{12}$ Evidentemente, una retórica similar se puede encontrar en naciones afiliadas a Irán o Hamas respecto de Israel y sus aliados.

Volviendo a La justicia de Dios, resulta bastante ilustrativo el repaso que Rubial hace de la célebre recopilación hagiográfica de Jacobo de la Vorágine, Leyenda dorada. Más que simples e inocentes relatos hagiográficos, estas historias pueden considerarse verdaderas "sagas de horror" (p. 188). En buena medida, la literatura hagiográfica, con su especial interés en el martirio, contribuyó a la conversión y el afianzamiento de la fe. Desde luego, siempre hubo controversias acerca de hasta qué grado el fiel debía emular o sólo rememorar y alabar el sufrimiento de Cristo y de los mártires. Lo importante de textos como Leyenda dorada es que la violencia narrada excitaba la emotividad de los fieles y alimentaba la compasión y los deseos de arrepentimiento (p. 189). Así pues, la efectividad de la martirología depende fuertemente del morbo. Este morbo es particularmente específico del cristianismo romano, no tanto por la figura de los santos como por el componente patético en estas narraciones, un elemento fundamental en la construcción de la religiosidad popular e iconográfica del catolicismo, sobre todo a partir del siglo XIII. El morbo, parece, sigue vigente: varias redes sociales han dado cuenta de reuniones de ciudadanos israelíes en algunas colinas para atestiguar, desde unas butacas, los bombardeos sobre territorios palestinos... ${ }^{13}$ Es una mórbida

${ }^{11}$ Cf. Raphael Ahren, "Dermer: IDF deserves Nobel Peace Prize for 'unimaginable restraint”, Timesofisrael.com, 22 de julio de 2014.

${ }^{12}$ Cf. Robert Fisk, “¿El Nobel de la Paz al ejército israelí?”, La Jornada, 11 de agosto de 2014.

${ }^{13}$ Adam Withnall, "Israel-Gaza conflict: 'Sderot cinema' image shows Israelis with popcorn and chairs 'cheering as missiles strike Palestinian targets", The Independent, 13 de julio de 2014. 
versión moderna de toda la pintura europea que representaba las cruentas victorias de los cruzados.

Reflexionar sobre la violencia física y simbólica de los discursos del cristianismo también supone reparar en nuestras propias percepciones, en nuestras visualizaciones en torno de nosotros y los otros. La violencia discursiva y hagiográfica no se agotó al concluir la Edad Media, sencillamente porque ella forma parte de nuestra realidad cotidiana e inmediata. Ante esta violencia diaria, intentamos en vano aspirar a la inconsecuente paciencia de Job y terminamos por reproducir los actos de la violencia simbólica y discursiva de los santos estudiados por $\mathrm{Ru}-$ bial, y por invocar las identidades religiosas eternamente en pugna. De este modo, el subtítulo de la obra de Rubial apunta no sólo a la figura de los santos, sino también, en cierto sentido, a la de "tipos" que se desarrollaron sobre todo entre los siglos XIII y XVIII. Son tipos a los que todavía seguimos respondiendo.

\section{Bibliografía}

Aciprensa, "El purgatorio: purificación necesaria para el encuentro con Dios", s.f. [www.aciprensa.com/Docum/cat-purgato.htm, consultado el 20 de julio de 2014].

Ahren, Raphael, "Dermer: IDF deserves Nobel Peace Prize for 'unimaginable restraint", Timesofisrael.com, 22 de julio de 2014. [www.timesofisrael.com/dermer-idf-deserves-nobel-peace-prizefor-unimaginable-restraint/, consultado el 4 de agosto de 2014.] Aristegui Noticias, "'Holocausto palestino en Gaza', artículo de Fidel Castro", 5 de agosto de 2014. [aristeguinoticias.com/0508/ mundo/holocausto-palestino-en-gaza-articulo-de-fidel-castro/, consultado el 6 de agosto de 2014.]

Bedoya, Juan G., "El Papa se enreda con el purgatorio", El País, 13 de enero de 2011. [elpais.com/diario/2011/01/13/sociedad/1294873211_850215.html, consultado el 20 de julio de 2014.] Bush, George W., “Text of President Bush's 2002 State of the Union Address", The Washington Post, 29 de enero de 2002. [www. washingtonpost.com/wp-srv/onpolitics/transcripts/sou012902. htm, consultado el 2 de agosto de 2014.]

Bush, George W., "9/11 Address to the Nation: A Great People has been Moved to Defend a Great Nation”, Americanrethoric. 
com, 11 de septiembre de 2011. [www.americanrhetoric.com/ speeches/gwbush911addresstothenation.htm, consultado el 2 de agosto de 2014.]

FIsK, Robert, “¿El Nobel de la Paz al ejército israelí??, La Jornada, 11 de agosto de 2014. [www.jornada.unam.mx/ultimas/2014/08/11/ el-nobel-de-la-paz-al-ejercito-israeli-541.html, consultado el 6 de agosto de 2014.]

Juan Pablo II, "El infierno como rechazo definitivo de Dios", Aciprensa, 21 de julio de 1999. [www.aciprensa.com/Docum/ cat-infierno.htm, consultado el 20 de julio de 2014.]

La Jornada, "Decide el Vaticano abolir el limbo", 21 de abril de 2007. [www.jornada.unam.mx/2007/04/21/index.php?section=socie dad\&article $=038 \mathrm{n} 1 \mathrm{soc}$, consultado el 20 de julio de 2014.]

Nadal, Alejandro, "Gaza: los designios de Israel”, La Jornada, 6 de agosto de 2014. [www.jornada.unam.mx/2014/08/06/ opinion/026a1eco, consultado el 6 de agosto de 2014.]

Radiopanamericana.com, "Papa Francisco: el infierno no existe y Adán y Eva son una fábula", 16 de abril de 2014. [www.radiopanamericana.com/noticias/4990/papa-francisco:-el-infiernono-existe-y-adan-y-eva-son-una-fabula, consultado el 7 de agosto de 2014.]

SAlOmON, Rivka, "Erdogan to mK Ayelet Shaked: You Have Hitler's Mentality”, Jerusalemonline.com, 13 de octubre de 2014. [www. jerusalemonline.com/news/middle-east/israel-and-the-middleeast/erdogan-to-mk-ayelet-shaked-you-have-hitlers-mentality-6490, consultado el 16 de julio de 2014.]

Turley, Jonathan, “'They Have To Die': Israeli Politician's Comments Calling For Killing of Mothers of Palestinians Trigger International Backlash”, Jonathanturley.org, 1 de julio de 2014. [jonathanturley.org/2014/07/17/they-have-to-die-israeli-politicians-comments-calling-for-killing-of-mothers-of-palestinianstrigger-international-backlash/, consultado el 15 de julio de 2014.]

WithNALl, Adam, "Israel-Gaza conflict: 'Sderot cinema' image shows Israelis with popcorn and chairs "cheering as missiles strike $\mathrm{Pa}$ lestinian targets”, The Independent, 13 de julio de 2014. [www. independent.co.uk/news/world/middle-east/israelgaza-conflictsderot-cinema-image-shows-israelis-with-popcorn-and-chairscheering-as-missiles-strike-palestinian-targets-9602704.html, consultado el 2 de agosto de 2014.] 